\title{
Tumores Carcinoides do Apêndice lleocecal: 2 Casos Clínicos
}

\section{Carcinoid Tumors of the Appendix lleocecal: 2 Case Reports}

Magda Alves, Teresa Salgueiro, Francisco Rodrigues ${ }^{1}$

\section{RESUMO}

Em 280 apendicectomias realizadas em 21 meses, foram diagnosticados incidentalmente 2 casos de tumores neuroendócrinos em mulheres com 12 e 89 anos. Ambas foram sujeitas a apendicectomia urgente por clínica de apendicite aguda com 12 horas e 5 dias de evolução respetivamente sem mais sintomatologia. O diagnóstico histológico da primeira doente foi tumor neuroendócrino com 2 mm de diâmetro e localização incomum, o corpo do apêndice. Na segunda doente um tumor de 1,5 cm no apex. Em ambas, dada a localização, o tamanho tumoral e margens livres, a apendicectomia foi curativa. Da análise dos dados e segundo a literatura, verificou-se que estes tumores são os mais frequentes no apêndice, ocorrendo principalmente em mulheres e com localizações mais comuns no apex e base seguindo-se o corpo.

PALAVRAS-CHAVE: Neoplasias do Apêndice; Tumor Carcinoide; Tumores Neuroendócrinos

\section{ABSTRACT}

In 21 months 280 appendectomies were performed, in which 2 cases of neuroendocrine tumors were diagnosed incidentally in women with 12 and 89 years. Both underwent urgent appendectomy for acute appendicitis with 12 hours and five days of evolution respectively without further symptoms. The histological diagnosis of the first patient was a neuroendocrine tumor with $2 \mathrm{~mm}$ diameter and unusual location, the body of the appendix. In the second patient a tumor of $1.5 \mathrm{~cm}$ at the apex. In both cases, giving the location, tumor size and free margins, appendectomy was curative. Data analysis and according to the literature, it was found that these tumors are most common in appendix occurring mainly in women and most common locations are the apex and base, following the body.

KEYWORDS: Appendiceal Neoplasms; Carcinoid Tumor; Neuroendocrine Tumors 


\section{INTRODUÇÃO}

O tumor carcinoide embora raro é o tipo histológico mais frequente no apêndice ileocecal. $\bigcirc$ pico de incidência ocorre na $3^{\mathrm{a}}-4^{\mathrm{a}}$ décadas, mas podem ocorrer em qualquer idade, inclusive em crianças. ${ }^{1-3} \mathrm{Na}$ sua maioria são um achado incidental após apendicectomia por apendicite aguda, sendo diagnosticados histologicamente. São indolentes e as metástases ( $T>2 \mathrm{~cm}$ ) são habitualmente locoregionais. ${ }^{2}$ Geralmente o prognóstico é excelente se a doença é local.

\section{CASO CLÍNICO 1}

Doente do sexo feminino de 12 anos; saudável; com antecedentes familiares irrelevantes.

Recorre ao serviço de urgência por dor no quadrante inferior direito do abdómen com 12 h de evolução acompanhado de febre $\left(38^{\circ} \mathrm{C}\right)$ e náuseas.

Objetivamente apresentava sinal de Blumberg, não sendo palpável qualquer massa/organomegalia nem apresentava outras alterações.

Analiticamente: Leucocitose e neutrofilia, proteína C-reativa (PCR) normal.

Foi internada com a hipótese diagnóstica de apendicite aguda.

Foi submetida a laparotomia de McBurney: apêndice fleimonoso, sem outras alterações macroscópicas, com realização posterior de apendicectomia.

A evolução no pós-operatório foi favorável, tendo alta após $24 \mathrm{~h}$, clinicamente bem.

A anatomia patológica revelou um apêndice fleimonoso com um tumor carcinoide T2NOMO com $2 \mathrm{~mm}$ no corpo apendicular (Fig. 1).

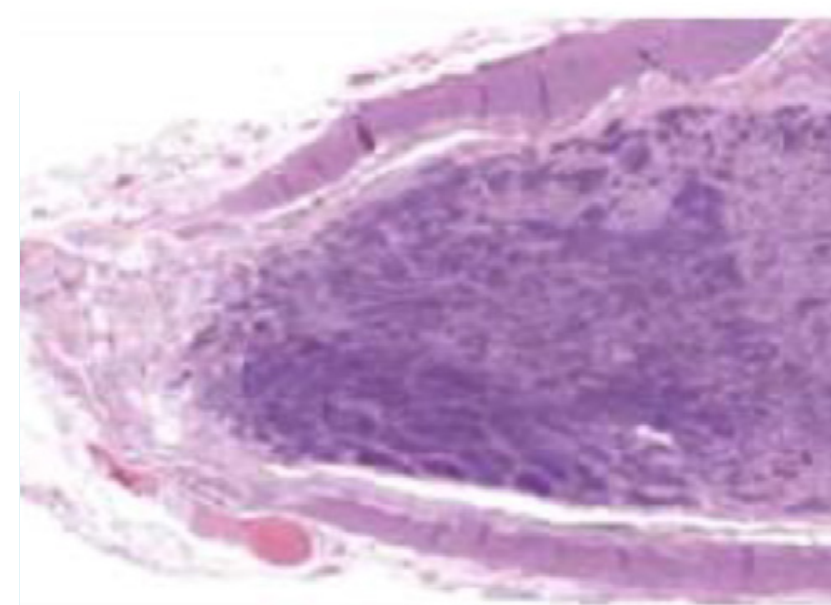

FIGURA 1. Caso clínico 1- anatomia patológica: apêndice fleimonoso; tumor carcinoide T2NOMO com $2 \mathrm{~mm}$ no corpo apendicular.

\section{CASO CLÍNICO 2}

Doente do sexo feminino de 89 anos, com antecedentes irrelevantes.

Recorre ao serviço de urgência por quadro de dor no quadrante inferior direito do abdómen com 5 dias de evolução, sem outra sintomatologia associada.

Objetivamente apresentava sinal de Blumberg sem massas nem organomegalias ou outros achados relevantes.

Analiticamente: Leucocitose e neutrofilia, PCR 5,6.

Foi internada com a hipótese diagnóstica de apendicite aguda.

Foi submetida a laparotomia de McBurney: apêndice supurado, sem outras alterações macroscópicas. Realizou-se apendicectomia.

A evolução no pós-operatório decorreu sem intercorrências, tendo alta após 24 h, clinicamente bem.

A anatomia patológica confirmou tratar-se de um apêndice supurado, no entanto foi diagnosticado um tumor carcinoide bem diferenciado $1,5 \mathrm{~cm}$ no apex T1NOMO (Fig. 2).

\section{DISCUSSÃO}

Os tumores carcinoides são tumores neuroendócrinos raros.

Podem ser encontrados no intestino, estômago e pulmão mas a localização mais comum é no apêndice ileocecal (Fig. 3).

De 280 apendicectomias realizadas no serviço de cirurgia geral do Hospital de Vila Franca de Xira entre 2013 e 2014, foram diagnosticados 2 tumores carcinoides $(0,7 \%)$.

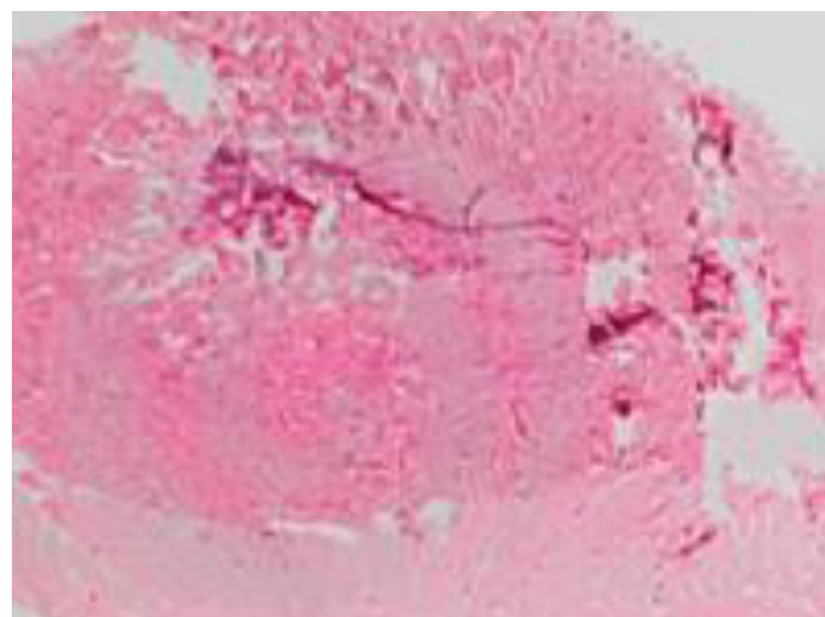

FIGURA 2. Caso clínico 2 - anatomia patológica: apêndice supurado; tumor carcinoide bem diferenciado $1,5 \mathrm{~cm}$ no apex T1NOM. 


\section{PARTE DO APARELHO DIGESTIVO}

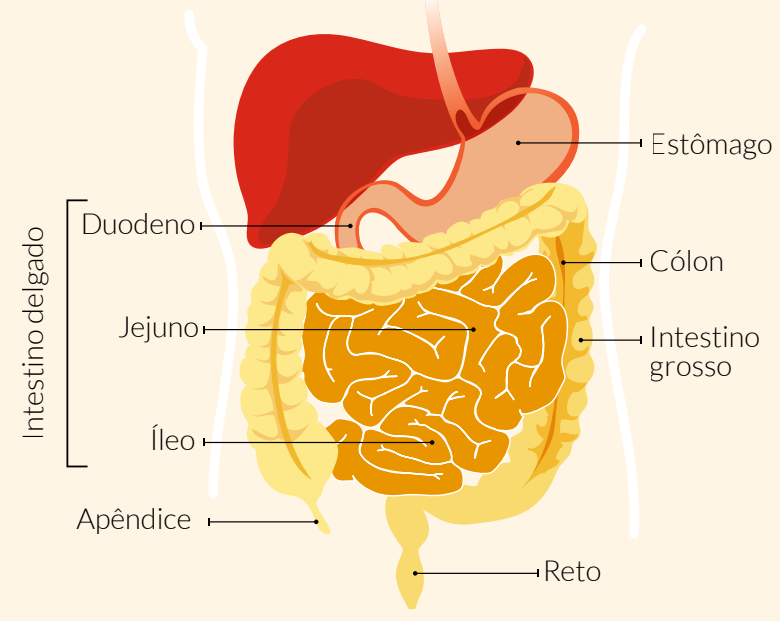

FIGURA 3. Localizações mais frequentes dos tumores carcinoides.

De acordo com a literatura, são menos comuns em crianças, apresentando características clínicas menos específicas mas em tudo semelhantes a um quadro de apendicite aguda.

Habitualmente o diagnóstico é incidental intra-operatório ou dado pelo exame histológico (forma diagnóstica mais comum).

Geralmente são tumores benignos, embora alguns apresentem um comportamento potencialmente maligno, podendo mesmo metastizar, dependendo do tamanho, estádio e tipo histológico e da localização.

No que respeita ao tratamento é necessário entrar em linha de conta com as dimensões e a localização do tumor, a fim de se considerar a intervenção cirúrgica curativa. Assim sendo, em tumores inferiores a $1 \mathrm{~cm}$ de qualquer localização e sem invasão do mesoapêndice a apendicectomia é considerada curativa. É igualmente considerado em tumores com 1-2 cm localizados no corpo ou apex, sem invasão do mesoapêndice. A hemicolectomia direita está indicada caso o tumor compreenda dimensões entre $1-2 \mathrm{~cm}$ ou $>2 \mathrm{~cm}$ e se localize na base com invasão do mesoapêndice. ${ }^{1-3}$

Salienta-se assim que em ambos os casos os tumores carcinoides foram um achado incidental cujo diagnóstico foi histológico, em doentes em faixas etárias distintas.

A apendicectomia foi curativa em ambas, tendo em conta o tamanho, a localização e as margens livres, ainda que com estadiamentos TNM diferentes.

CONFLITOS DE INTERESSE: Os autores declaram a inexistência de conflitos de interesse na realização do trabalho.

FONTES DE FINANCIAMENTO: Não existiram fontes externas de financiamento para a realização deste artigo.

PROTEÇÃO DE PESSOAS E ANIMAIS: Os autores declaram que os procedimentos seguidos estavam de acordo com os regulamentos estabelecidos pelos responsáveis da Comissão de Investigação Clínica e Ética e de acordo com a Declaração de Helsínquia da Associação Médica Mundial.

CONFIDENCIALIDADE DOS DADOS: Os autores declaram ter seguido os protocolos do seu centro de trabatho acerca da publicação dos dados de doentes.

\section{REFERÊNCIAS}

1. Gu Y, Wang N, Xu H. Carcinoid tumor of the appendix: A case report. Oncol Lett. 2015;9:2401-3.

2. Kulke MH, Mayer RJ. Carcinoid tumors. N Engl J Med.1999; 340:858-68

3. Rindi G, Arnold R, Bosman FT. Nomenclature and classification of neuroendocrine neoplasms of the digestive system. In: Bosman TF, Carneiro F, Hruban RH, Theise ND, editors. WHO Classification of Tumours of the Digestive System. 4th ed. Lyon: International Agency for Research on Cancer; 2010.p.13 